\section{Las lagunas estratigráficas y las superficies negativas en arqueología}

José I. Murillo Fragero, M. a Ángeles Utrero Agudo' $\mathrm{IH}, \mathrm{CSIC}$
Las diferentes intervenciones efectuadas por nuestro equipo ${ }^{2}$ dentro del marco de la Arqueología de la Arquitectura han provocado frecuentes discusiones internas de diferente índole durante el desarrollo de los trabajos, tanto frente al objeto de estudio, cuando se lleva a cabo la toma de datos, como durante la labor posterior de análisis y síntesis de la información obtenida.

Nuestra intención es presentar una serie de reflexiones fruto de los trabajos arqueológicos que durante estos últimos años hemos realizado en edificios históricos muy diversos morfológica y cronológicamente, aunque la mayoría se caracterizan por desempeñar una función cultual. La aplicación del método estratigráfico a la comprensión de los alzados construidos implicó la aparición de cuestiones que afectaban tanto a su cuerpo teórico como a su puesta en práctica. Las lecturas de sus paramentos tenían como objetivo principal obtener una secuencia estratigráfica completa que permitiese reconstruir su vida histórico-constructiva. Pero en casi todos los casos nos hemos encontrado con problemas que han sido, en cierta medida, el motor de las reflexiones metodológicas que pretendemos presentar a continuación. Entre todas esas cuestiones surgidas, optamos en un principio por tratar el concepto de hiato a merced de las dudas que nos provocaba su uso e identificación. Sin embargo, a medida que nos adentramos en la elaboración de este trabajo, el camino fue conduciéndonos paulatinamente al tema de las lagunas estratigráficas, cuya importancia a la hora de precisar las unidades y etapas que configuran los conjuntos estudiados hace necesario, en nuestra opinión, profundizar en su conocimiento.

Por lo tanto, a partir del acercamiento al término de hiato, fuimos encontrando otra serie de conceptos que podían llevar a confusión en el proceso de documentación de la secuencia estratigráfica. Por ejemplo, no se debe desestimar la individualización y uso de las superficies, las cuales cuando constituyen unidades negativas no reflejan hiatos (ausencia de deposición estratigráfica), sino vacíos erosionales (desaparición de una deposición previamente ocurrida). Por otro lado, la constatación de unidades que podríamos denominar «unidades recuperadas», aquellas que existieron y que conocemos gracias a su documentación en fuentes complementarias (fotografías, textos), nos enseña que los resultados de las lecturas están condicionados por los elementos que conserva el edificio. En este sentido, debemos tener en cuenta que tanto las fuentes escritas como las materiales (edificio) son siempre parciales, reflejo selectivo de la acción del tiempo. Las fuertes transformaciones históricas

\footnotetext{
${ }^{2}$ Dirigido por L. Caballero Zoreda, IH, CSIC.

1 Becaria Doctoral de la Fundación de Caja Madrid. Agradecemos las sugerencias y comentarios realizados por L. Caballero Zoreda.
} 
$y$, sobre todo, las frecuentes y, a menudo, agresivas restauraciones contemporáneas pueden llevarnos a obviar la existencia de actividades de las que es imposible reconocer sus huellas materiales.

\section{LAGUNAS ESTRATIGRÁFICAS: DEFINICIÓN}

Como ya es conocido, el método estratigráfico arqueológico es la traslación del sistema de análisis del subsuelo geológico a nuestra disciplina. Posteriormente, el análisis estratigráfico se ha incorporado y adaptado al estudio de los edificios históricos. Por lo tanto, diferentes objetos de estudio, suelo y construcción, están amparados por un sistema metodológico de análisis común.

Por ello y en relación a la cuestión que aquí nos ocupa, para definir dentro del ámbito de la arqueología de la arquitectura los hiatos, queremos, primero, presentar lo que entienden en este sentido la geología y la arqueología respectivamente, para, seguidamente, hacer una relación de diferentes problemas a los que nos hemos enfrentado durante el análisis de distintos edificios y explicar cómo hemos intentado solucionarlos.

De acuerdo a la definición expuesta por los geólogos Dabrio y Hernando $(2003)^{3}$, dentro de la estratigrafía geológica se identifica la laguna o discontinuidad estratigráfica como el lapso de tiempo no representado por sedimentos. Este concepto encierra a su vez dos subtipos de discontinuidad: el vacío erosional, entendido como un espacio de tiempo no representado por haber sufrido la acción de la erosión; y el hiato, como espacio de tiempo sin representar por no haber tenido lugar la sedimentación correspondiente.

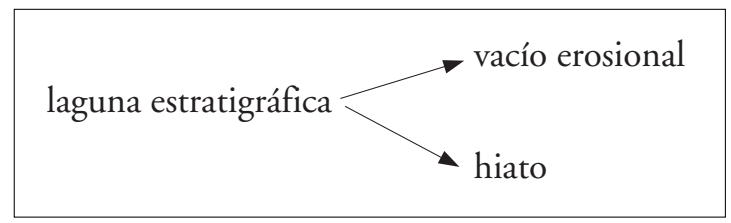

Es decir, mientras en el caso del hiato, la sedimentación no se produce, en el del vacío erosional, la deposición, por el contrario, sí tuvo lugar, pero no tiene refrendo material por causa de alteraciones posteriores que modificaron el proceso de estratificación.

Estos presupuestos se basan en la ausencia de columnas estratigráficas geológicas completas en los registros sedimentarios de aquellas regiones estudiadas, lo que ha dado lugar a la composición de estratigrafías parciales. Esto es razonable si consideramos que la sedimentación no es un

3 Principio de los fenómenos de la discontinuidad del registro estratigráfico $y$ de la mayor importancia de los hiatos sobre el registro sedimentario. proceso uniforme y continuo y que está afectado por los fenómenos de erosión que son siempre irregulares.

Por el contrario, de la lectura de los manuales arqueológicos se deduce una heterogeneidad en el uso de los términos que designan los fenómenos de discontinuidad. De hecho, las referencias con las que contamos son escasas. Harris (1991: 85) únicamente se refiere a las discontinuidades como elementos interfaciales o unidades negativas que son el resultado de la destrucción de la estratigrafía previa, mientras que reserva el término de «interfacies» ${ }^{4}$ para hablar de los lechos o superficies de las unidades positivas. Carandini (1997: 77) asimila las lagunas estratigráficas, las «interfacies» y las superficies en sí como un mismo fenómeno. Sólo en Caballero (1995: 40 y 1996: 63) encontramos una breve referencia al hiato de acuerdo a la aplicación de la estratigrafía al análisis murario. De acuerdo con la pauta de la definición geológica, Caballero entiende incorrectamente el hiato trastocándolo con el de vacío erosional, es decir, como «cortes con los que han desaparecido elementos que documentaban fases $y$ actividades desde entonces no representadas.

En conclusión, en geología el hiato se identifica con la ausencia de sedimentación, mientras que en Arqueología de la Arquitectura, de la única referencia que tenemos, la de Caballero (1995 y 1996), se deduce un uso incorrecto del término hiato como vacío erosional, es decir, como una superficie negativa creada por la desaparición de una unidad previa. Quizás la acepción vulgar del término hiato, equivalente a corte, llevó a Caballero a equipararlo con el contenido completo del principio de las discontinuidades. Por ello, proponemos recuperar el uso preciso de la terminología geológica si, con las necesarias matizaciones, ésta se presenta como adecuada a la experiencia estratigráfica en la arquitectura.

\section{LAGUNAS ESTRATIGRÁFICAS: EJEMPLOS}

Con los siguientes ejemplos queremos hacer hincapié en cómo las lagunas estratigráficas se documentan gracias a la individualización de las superficies negativas y cómo hay ciertos procesos históricos que, aunque no han dejado huella en el registro estratigráfico, por lo que no pueden tratarse como discontinuidades, deben ser tenidos en cuenta a la hora de reconstruir la evolución del yacimiento.

\section{Superficies Negativas o de Corte}

San Millán de la Cogolla, Suso (La Rioja). La conocida iglesia de Suso ha gozado de una breve comprensión evolutiva de su estructura ${ }^{5}$, la cual se intentó fijar, corregir

\footnotetext{
4 Sobre el uso y traducción de los términos interfaz e interfacies, nos remitimos a las observaciones realizadas por Caballero (1996: 72, nota 8). 5 Comparar Gómez Moreno (1919) y Puertas Tricas (1979).
} 


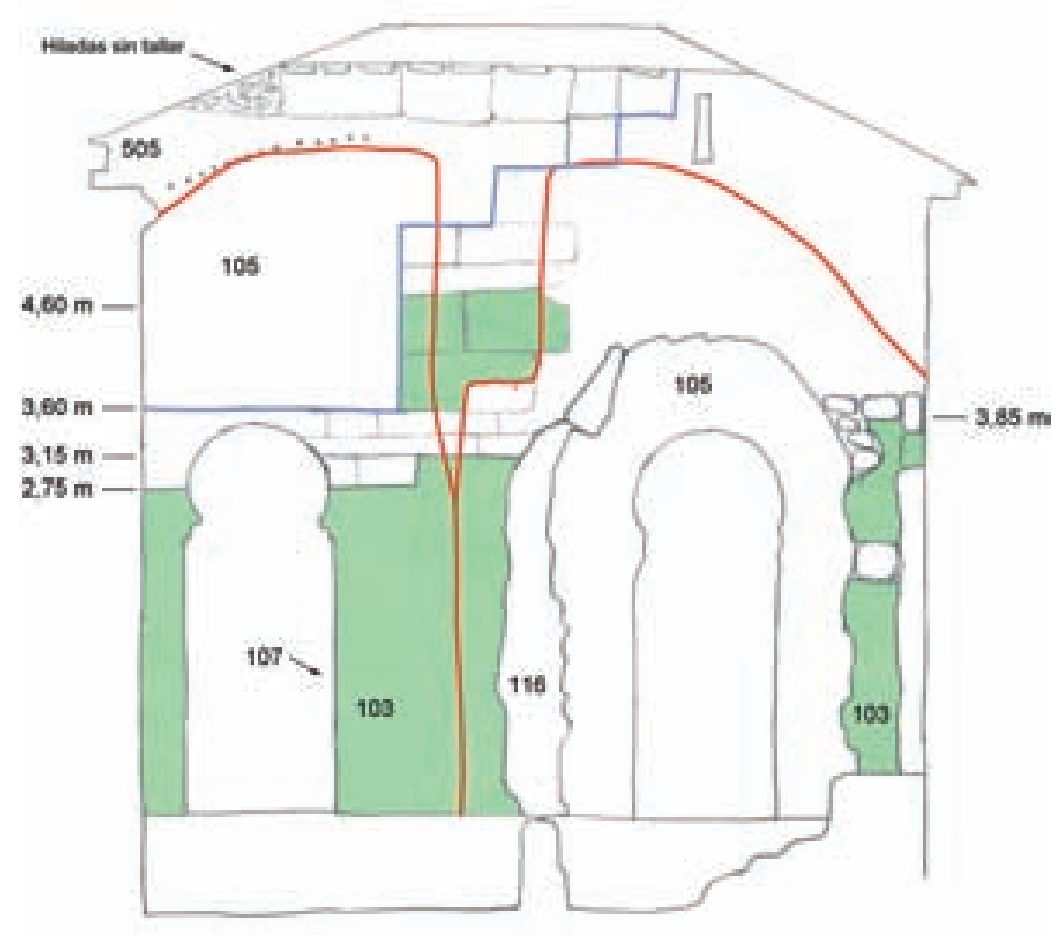

Fig. 1. Suso, Lectura del testero oriental

y enriquecer con la lectura de paramentos efectuada recientemente dentro y, en cierta medida, posteriormente al programa de restauración que impulsó su realización (CABALLERO, 2002 y 2005). De acuerdo a los resultados de la lectura de sus alzados, un fuerte incendio parece haber sido el causante del deterioro del material empleado en su construcción. La superficie interna de los paramentos pertenecientes a las dos etapas prerrománicas de la iglesia ${ }^{6}$ presenta, en consecuencia, una notable degradación apreciable en las aristas escantilladas de los sillares, en la exfoliación y en los cambios de colores de sus caras o superficies. Este hecho podría corresponder al momento histórico recogido en las fuentes documentales, las cuales culpan a las razias dirigidas por el caudillo Almanzor de la destrucción intencionada del templo en el año 1002.

La existencia de algunas estructuras originales, hoy perdidas, se puede constatar precisamente gracias al incendio. La ausencia del color rojizo y de la exfoliación de la sillería caliza constituye una "huella en blanco» o «negativo» que sirve como guía o indicador de la presencia primitiva de un elemento que actuó como obstáculo al impacto del fuego. Así ocurre en la fachada oriental (Fig. 1), donde una

${ }^{6}$ A la primera obra prerrománica pertenecen la parte inferior de los muros de sillería en arenisca que se extienden hacia el oeste, posiblemente hasta el pilar que marca la desviación de la iglesia hacia el norte. A la segunda, ambas estancias, alzadas en sillería caliza y con bóvedas de nervios, y el primer tramo este del aula de dos naves con cubiertas de madera. franja vertical (A 116) refleja la construcción de un muro en un momento ligeramente posterior a la segunda iglesia prerrománica, pues su pérdida o desmonte ha dejado una marca, pero no enjarjes que permitan confirmar su coetaneidad. Por lo tanto, la constatación de este muro a través de su huella introduce una nueva etapa en la secuencia histórica del edificio: una obra posterior a la segunda iglesia, conocida generalmente como mozárabe, y previa al incendio, atribuido a Almanzor. Se trata de una superficie negativa, un vacío erosional, que permite identificar una estructura desaparecida posiblemente como resultado de las obras de restauración efectuadas en época contemporánea si nos atenemos a la secuencia estratigráfica resultante.

Del mismo modo, la impronta del fuego también se convierte en un indicador para etapas posteriores, las cuales no sufrieron su efecto. Así, la obra protorrománica ${ }^{7}$, como todas las ejecutadas después, no muestra evidencias de haber sido atacada por un incendio. Por lo tanto, una superficie negativa se convierte en una unidad decisiva que marca de manera muy clara un antes y un después en la vida de la construcción, independientemente de que podamos hacerla corresponder con una causa histórica precisa ${ }^{8}$.

7 Tramo occidental del aula. Inicio marcado por la desviación de su eje E-O.

${ }^{8}$ Como ya refleja Ubieto (1973) al cuestionar la autoría de Almanzor a partir del estudio de las fuentes. 
San Pantaleón de losa (Burgos). El análisis del conjunto erigido en Losa (CABALLERO, 2003c y CABALlero y otros, 2005) evidencia la presencia de varios cuerpos constructivos alzados en distintos momentos históricos. Los correspondientes a la etapa más antigua de la ermita son los integrados por una pequeña nave con ábside semicircular y cubierta abovedada que, por presentar sus materiales constructivos claras huellas de reutilización, tanto en la fábrica de sillería como en su escultura de factura románica, nos permite llevar la fase inicial a un momento post-románico.

En el lateral norte de la nave primigenia de la ermita se conserva el arranque de un muro que adscribimos a la etapa original del edificio y que permite plantear la reconstrucción espacial de esta parte y proponer, con la ayuda de otros argumentos, como es la presencia de un vano norte original en el mismo muro, la existencia de un ámbito al norte de la nave. Por lo tanto, el corte o destrucción del muro es una superficie negativa, discontinuidad que refleja la ruina de esta obra (Fig. 2).
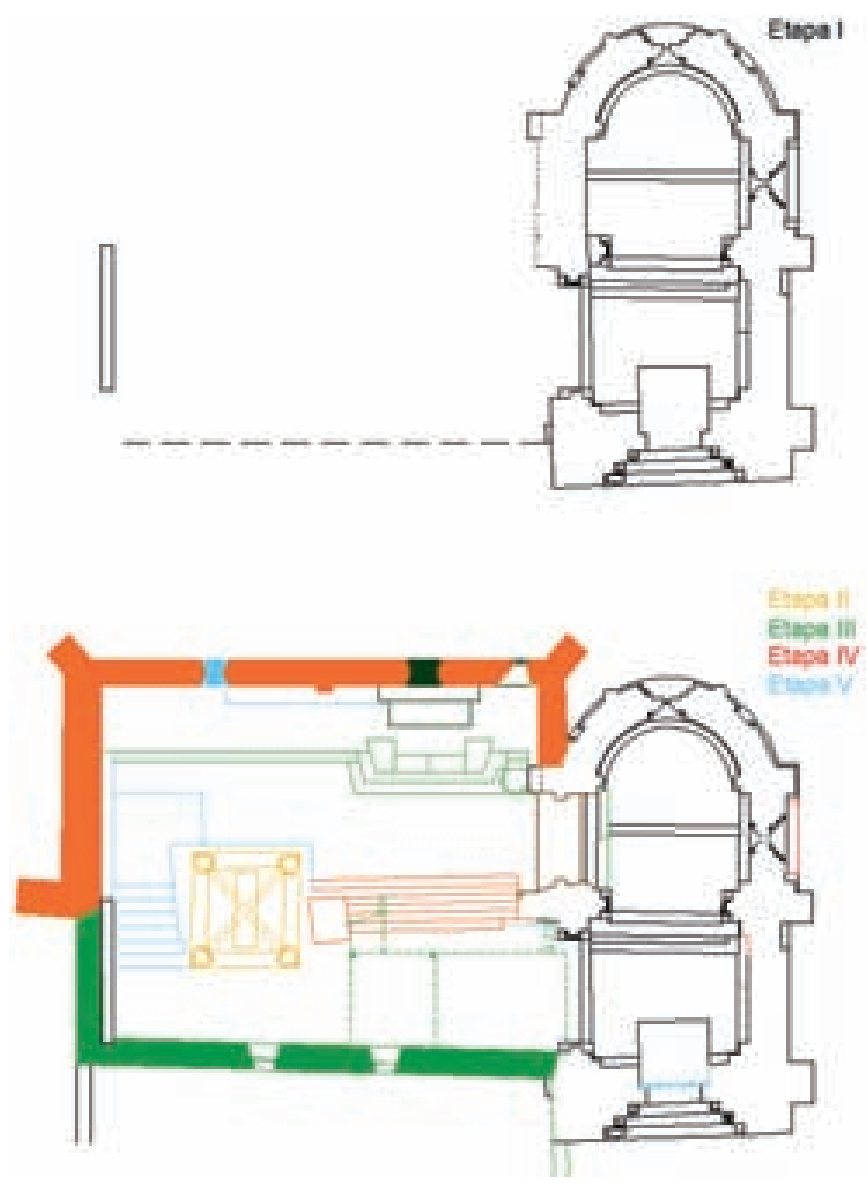

Fig. 2. Losa, Plantas de la Etapa I con la posible reconstrucción de la nave norte y de las siguientes etapas

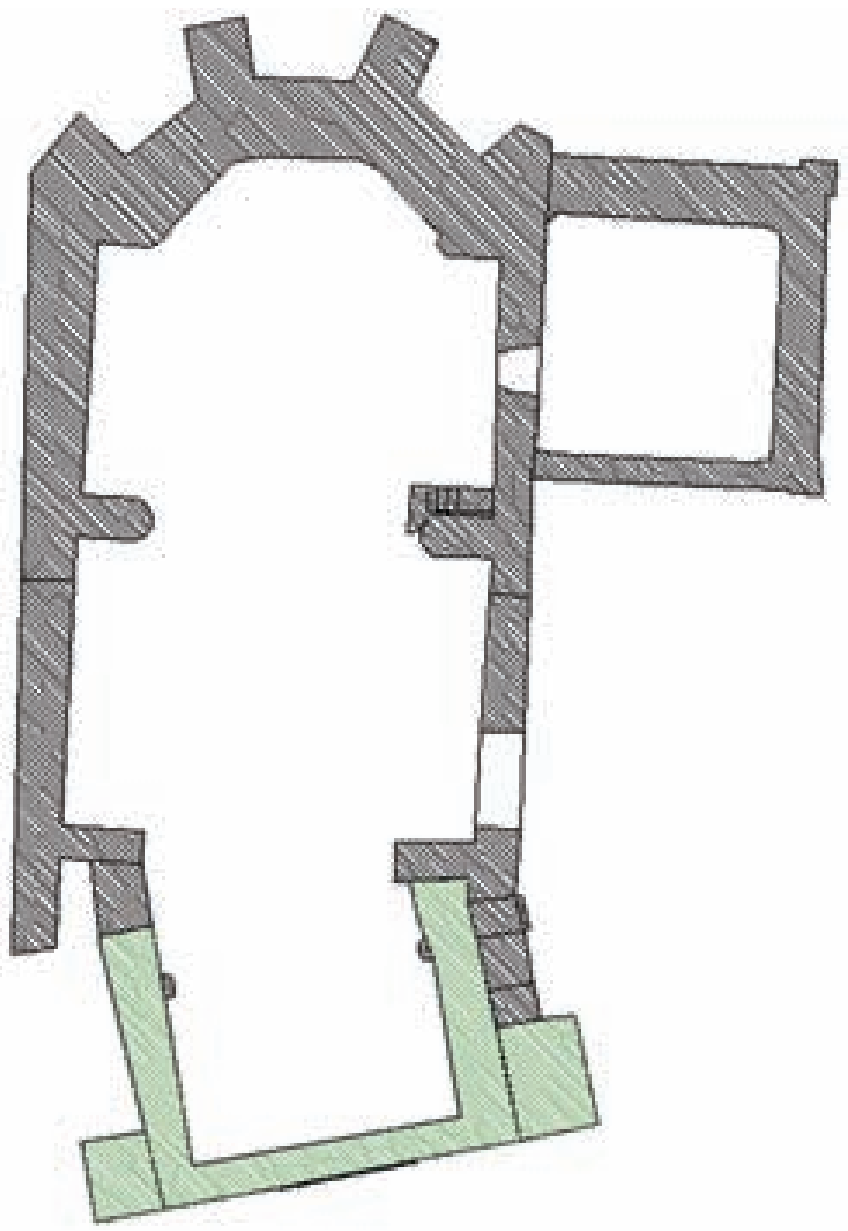

Fig. 3. Viñaspre, Planta de la iglesia con la etapa bajomedieval de los pies diferenciada

Nuestra Señora de la Asunción de Viñaspre (Álava). Este edificio encierra fundamentalmente dos grandes etapas edilicias, de las cuales la moderna pretendía la sustitución total de las previas. De la obra original bajomedieval se conservan los pies de la nave, mientras que de la nueva construcción adscrita a época moderna se llegó a construir el ábside y los dos tramos abovedados de la nave (Fig. 3). La lectura (CABALlero, 2003a) testimonia cómo el proceso constructivo contemplaba el desmonte de la obra antigua de manera simultánea al alzado de la nueva, cuyo estado inacabado favoreció la conservación de los tramos bajomedievales mencionados. La huella de su desmonte es, de nuevo, una superficie negativa. No se acometieron otras empresas edilicias entre ambos momentos históricos: la iglesia bajomedieval se mantuvo en uso hasta el comienzo de las modificaciones de época moderna y parcialmente hasta nuestros días, constituyendo aún hoy el cierre occidental de la nave (Fig. 4). 


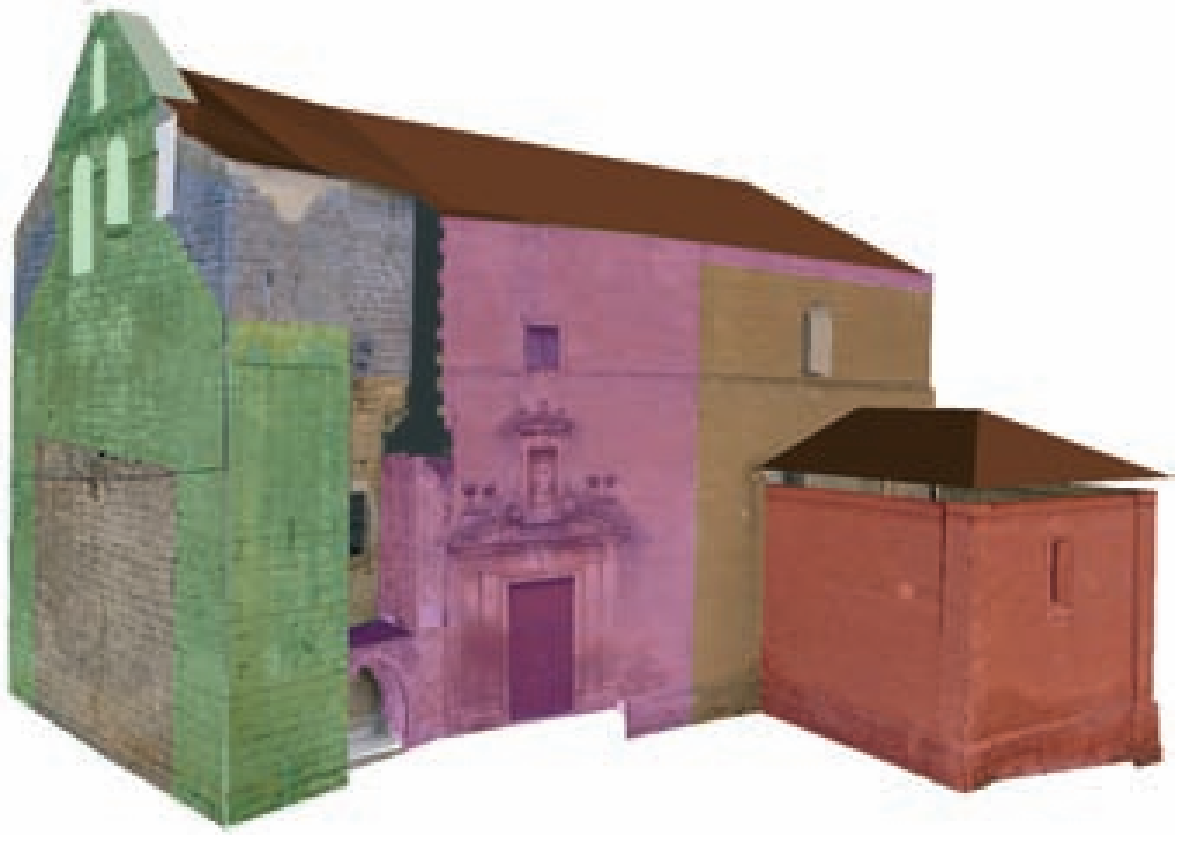

Fig. 4. Viñaspre, Vista axonométrica desde el Suroeste con las distintas etapas
Torre de la Iglesia de San Pedro el Viejo (Madrid). El análisis estratigráfico de la torre, el cual nos muestra en esencia un cuerpo unitario, permitió reconocer un interesante proceso constructivo (CABALlero y Murillo, 2004). El muro perimetral se ejecuta en dos tipos de técnicas paramentales que no significan dos etapas históricas. La lectura identifica un encofrado de calicanto forrado al exterior por un paramento de ladrillo en la zona basal. Desde el punto en que la escalera comienza a ser volada, paramento exterior e interior se alzan en ladrillo, por lo que la fábrica de calicanto queda oculta como núcleo del muro. La misma combinación de material se aprecia en el machón central rectangular. Entre ambos cuerpos, pertenecientes a un mismo proyecto de obra, y en la parte baja, discurre una estructura ejecutada en fábrica de adobe. Este cuerpo funciona como encofrado para la obra de calicanto y como soporte constructivo en el primer tramo de la torre, donde la escalera todavía no es volada y aprovecha el hueco abierto por él.

¿Cómo hemos podido establecer tal distinción? Función y proceso constructivo se entrelazan en la comprensión de las unidades de esta torre. El alzado de las tres fábricas acontece simultáneamente. El basamento de calicanto es contenido por el forro de ladrillo y, donde comienza la escalera, se introduce el adobe que acompaña a la obra hasta la altura donde la escalera se hace exenta. La identificación de la superficie dejada por el ladrillo de barro en el muro fraguado de calicanto durante la labor de desmonte (Fig. 5), simultánea a la realización del tramo bajo de la es-

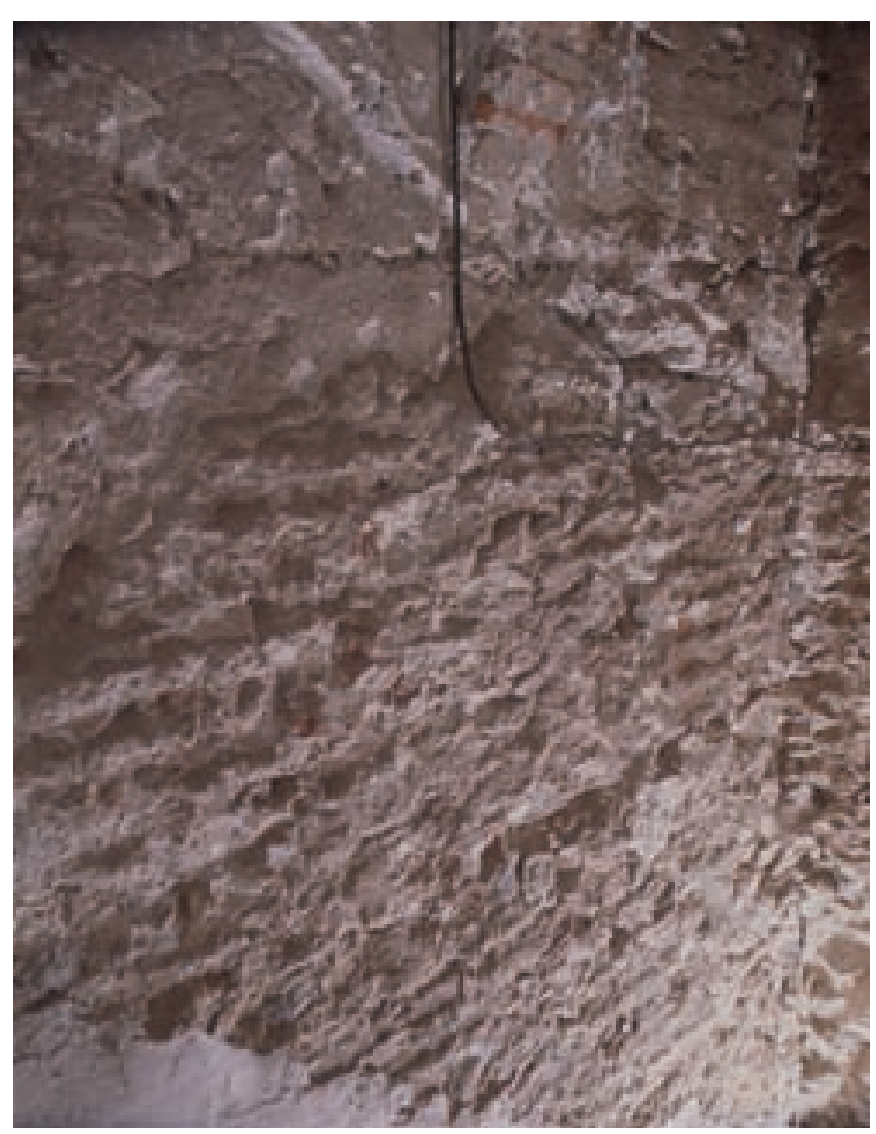

Fig. 5. San Pedro El Viejo, Huellas del desmonte de los adobes en la fábrica de calicanto 


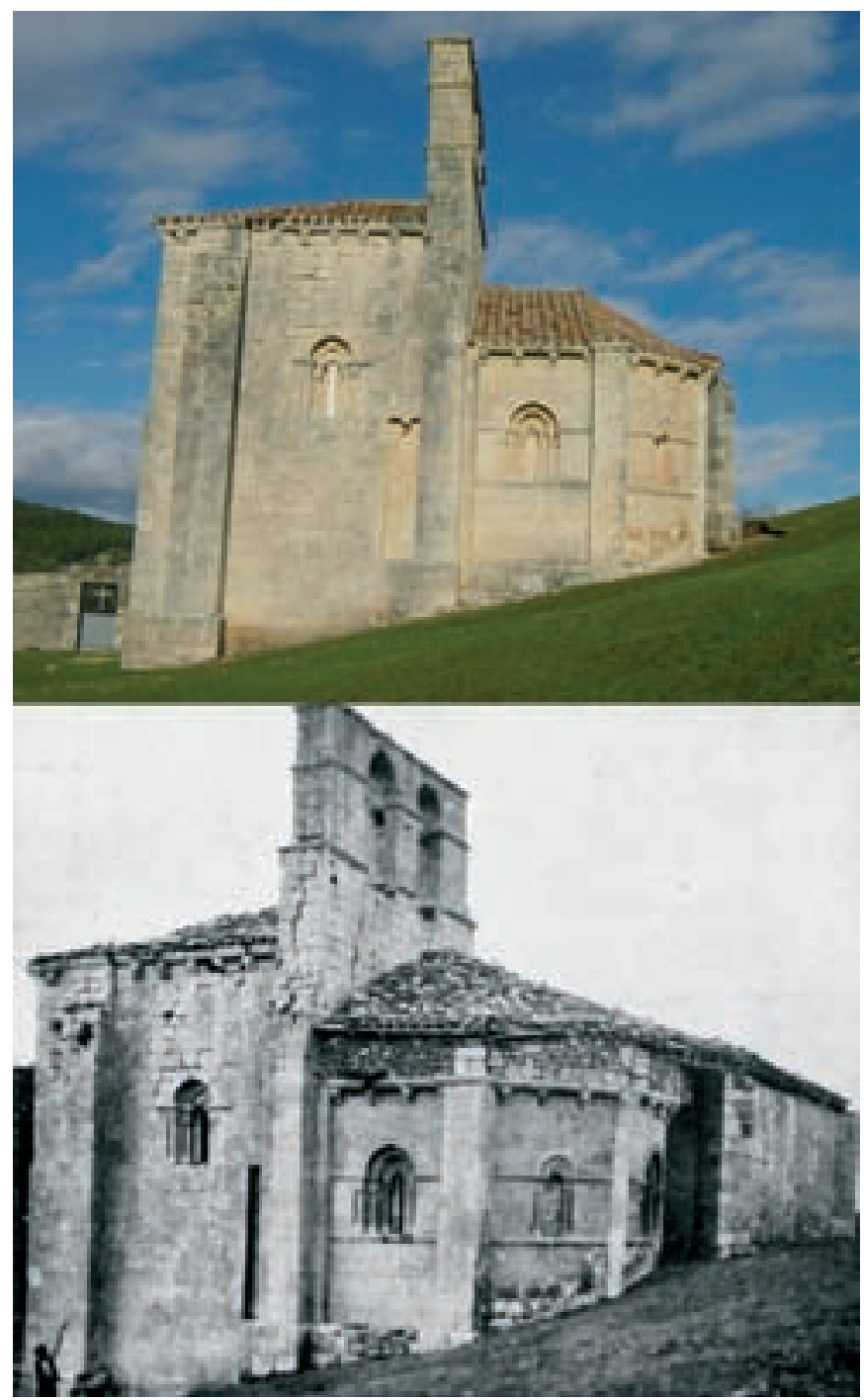

Fig. 6. Atán, Fachada occidental con la torre en su lado sur

calera, es el indicio de este proceso. Sus huellas sólo se conservan en el tramo inferior mencionado, desapareciendo donde comienza el vuelo de la escalera.

Iglesia de San Esteban de Atán (Lugo) ${ }^{9}$. La iglesia situada en el municipio de Atán se pretendía como románica de acuerdo a la tipología formal e iconográfica de sus motivos decorativos. Como más adelante exponemos, los resultados de la lectura paramental modificaron esta teoría al adscribir la construcción actual a un periodo bajomedieval muy posterior.

Lo único que nos queda en realidad de época románica es la torre, en la cual se constata una laguna estratigráfica. Las fuentes modernas nos informan de su uso hasta finales

9 Publicada en esta misma serie por Caballero y otros (2003). del XVIII. En la segunda mitad del siglo XIX, es desmochada con motivo de la construcción de la casa parroquial en este lado de la iglesia. Este hecho se reconoce en la superficie horizontal negativa bastante regular que recorre todo el perímetro de la torre y en el cambio de la técnica paramental entre ambas partes, inferior y superior (Fig. 6). Si se acometieron reformas constructivas de entidad entre el siglo XII y el XIX, sólo podremos conocer las que afectaron a la parte inferior conservada. De lo contrario, se han perdido para la historia, pues tampoco fueron recogidas en las fuentes escritas.

\section{2. "Unidades Recuperadas»}

El análisis estratigráfico de un edificio histórico requiere de la consulta de la documentación complementaria existente sobre el mismo. Los artículos de síntesis, las monografías, las memorias de restauración y los documentos custodiados en los archivos históricos pueden testimoniar acciones histórico-constructivas que nos ayuden a establecer y/o comprender la secuencia obtenida en la lectura del documento material, es decir, la construcción. Por lo tanto, en ellas podemos recuperar una serie de unidades que no se reflejan en el registro arqueológico. Descripciones, dibujos y fotografías deben ser valoradas de una forma crítica y complementaria, nunca determinante, en la labor de comprensión y datación de la arquitectura.

Iglesia de SAn Pantaleón de Losa (Burgos). En el análisis arqueológico de sus paramentos podemos reconocer dos fenómenos que a priori se prestan al uso del término de discontinuidad. En el ábside, la fábrica original de sillería soporta una cubierta de tejas contemporánea, adscripción que podemos confirmar gracias a las fotografías antiguas (ÍNIGUUEZ, 1941), las cuales nos permiten reconocer una fase intermedia hoy inapreciable en el registro material (Fig. 7). Se trata de un recrecido de mampostería realizado en un momento determinado para unificar las cubiertas del edificio. Las restauraciones efectuadas bajo el mando del arquitecto F. Íñiguez conllevaron posiblemente su desmonte al independizar de nuevo las cubiertas de cada cuerpo constructivo. El nuevo tejado del ábside se asienta directamente sobre los muros primitivos. De este modo, la documentación gráfica nos permite reconocer una unidad y una fase que hoy no existe. Se documenta la ausencia de una unidad, un vacío erosional, que no podemos reconocer con las herramientas estratigráficas, ya que el asiento de este recrecido y de la cubierta actual se efectúa en el mismo lugar, sobre el remate superior de los muros y no deja marca alguna.

El segundo fenómeno al que nos referimos se resume en la sospecha sobre la existencia de una iglesia previa, bien 


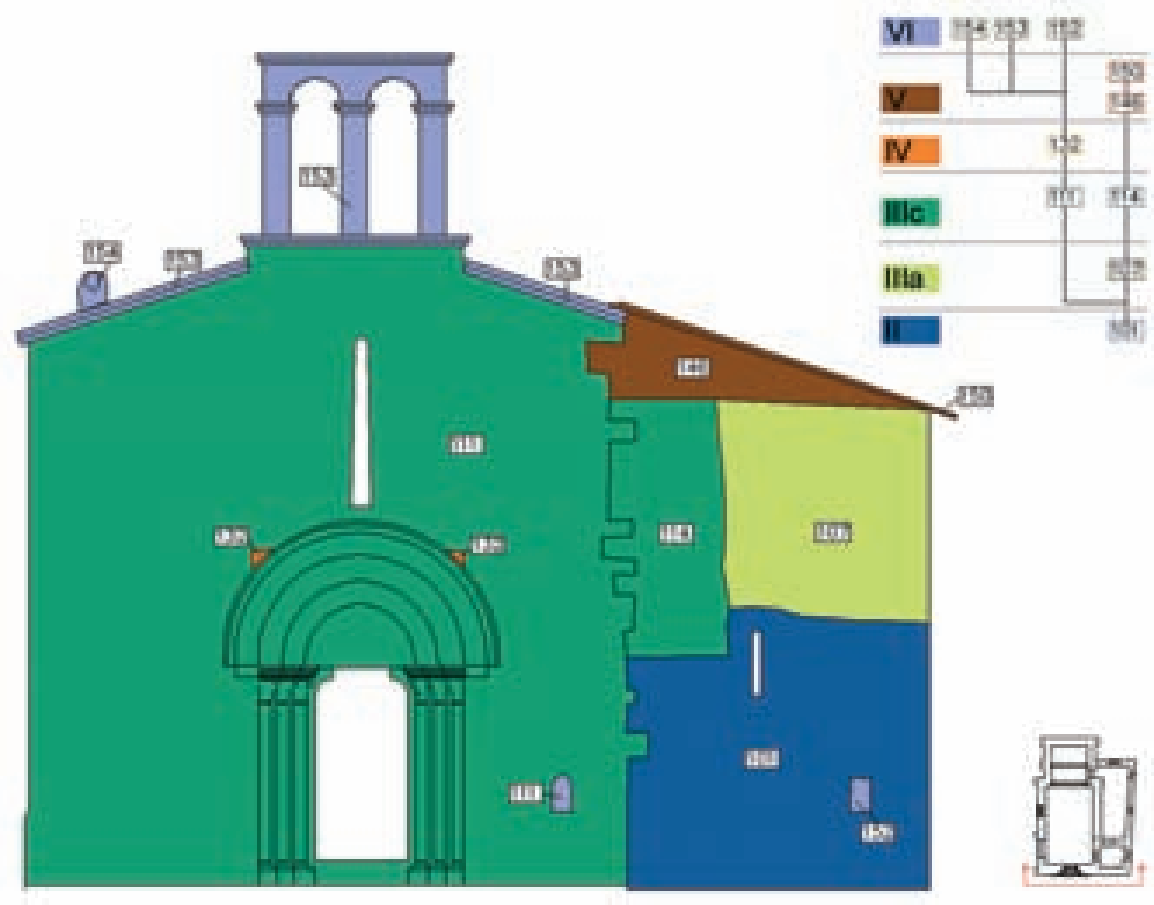

Fig. 8. Arlucea, Esquina suroeste de la torre de la iglesia

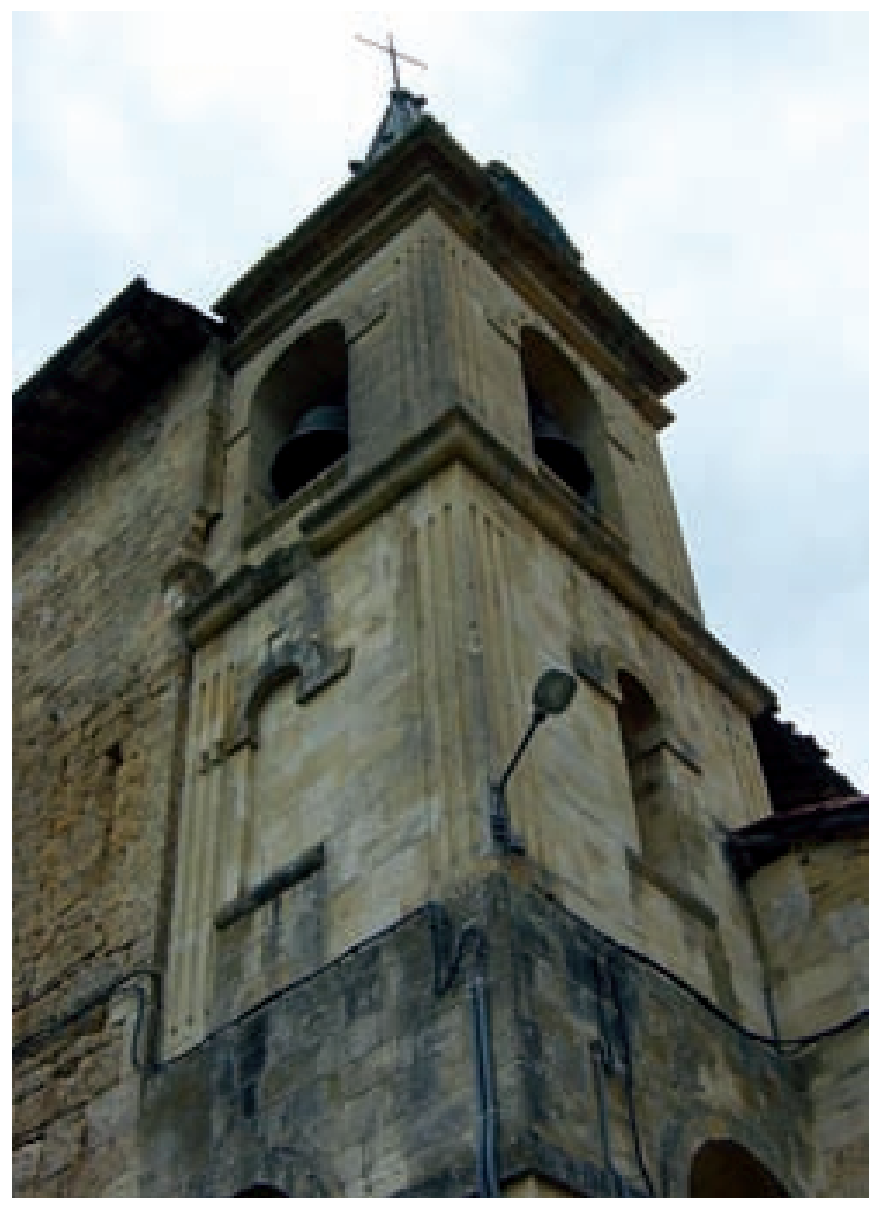

Fig. 7. Losa, Vista antigua (Íñiguez, 1941) y actual del ábside en el mismo lugar, bien en las proximidades de la actual. Tal posibilidad se basa en el carácter reutilizado de los materiales constructivos y decorativos, cuyo programa iconográfico confirmaría además una misma advocación, y en los datos que aportan los documentos de donación ${ }^{10}$, en los que se cita la iglesia de San Pantaleón con anterioridad a su consagración en 1207, fecha que aparece reflejada en el epígrafe, también posiblemente reutilizado, situado en el interior del edificio. A partir de todos estos datos parece evidente la presencia de uno o varios edificios anteriores, de los cuales desconocemos su ubicación, forma y relación con la iglesia estudiada ${ }^{11}$.

San Martín de Arlucea (Álava). Los Libros de Cuentas constituyen una rica fuente de información documental para la época moderna de la iglesia, en la que se ha constatado una amplia secuencia estratigráfica (CABALLERO, 2003b). En ellos se testimonia, entre otras actividades constructivas llevadas a cabo en el edificio, la existencia de una torre que sufre sucesivas restauraciones. La actual torre es unitaria y, además, su relación con diferentes partes de la iglesia, a las cuales se adosa, permite situar su construcción a comienzos del siglo XX (Fig. 8). Por lo tanto, la confrontación entre las

${ }^{10}$ Correspondientes a los años sucesivos de 1133, 1158 y 1178 (GómEZ GÓmEZ, 2002).

${ }^{11}$ El informe de excavación tampoco constata estructuras previas que puedan identificarse con un edificio cultual anterior en el lugar. 
fuentes escritas y los vestigios materiales manifiesta una contradicción que sólo puede ser resuelta de la siguiente manera: hubo una torre perdida, de la cual tampoco conocemos su ubicación, pues pudo estar donde la actual o en otro sitio, y que únicamente tenemos atestiguada en los Libros de Cuentas.

En consecuencia, tanto en Losa como en Arlucea, las fuentes escritas y gráficas permiten reconocer unidades y actividades sin reflejo material ni estratigráfico las cuales hemos denominado unidades recuperadas. Aunque corresponden a elementos perdidos, el hecho de que podamos conocerlos a través de fuentes complementarias los convierte en «unidades reconocibles». ¿Se deben entonces numerar como si fueran unidades estratigráficas convencionales, es decir, reconocidas a través del registro material? Creemos que deben ser expuestos en las conclusiones del análisis, pero su introducción en el listado de unidades es inadecuada y puede conducir a la confusión, pues, evidentemente, las unidades recuperadas en las fuentes carecen de relaciones físicas.

Iglesia de SAn Esteban de AtÁn (Lugo). La documentación escrita en la que se menciona la existencia de una iglesia prerrománica en Atán y el empleo de tres piezas consideradas como celosías adscritas a la misma cronología suscitó la lectura del edificio con el objetivo de intentar constatar estratigráficamente dicha etapa histórica. A estos indicios, se habían sumado unas estructuras anteriores aparecidas en la excavación previa del interior. Sin embargo, la lectura de sus paramentos contradecía esta hipótesis, pues la iglesia actual reutiliza elementos decorativos (capiteles y canecillos) y arquitectónicos (portadas) de época románica. La iglesia es, por lo tanto, de un momento posterior al siglo XII. Ante este cambio de cronología y la confirmación de que las celosías consideradas como prerrománicas no son tales, sino cruces caladas reempleadas en los muros modernos y contemporáneos, los argumentos originales fueron cayendo ${ }^{12}$. Sólo una de las piezas puede aceptarse como celosía prerrománica, pero su procedencia es, obviamente, incierta, por lo que no puede ser empleada para defender una iglesia prerrománica en el mismo solar.

De nuevo, nos encontramos con una iglesia que no corresponde al contenido de las fuentes escritas, lo que tampoco evita que el edificio al que éstas se refieren exista en un lugar cercano. El Atán que nosotros vemos no es el prerrománico, pero tampoco podemos confirmar dónde se encuentra éste.

\section{CONCLUSIONES}

A tenor de lo aquí expuesto, vemos cómo los hiatos corresponden a una ausencia de actividad que suponga estratificación en sí y, por ello, no son más que un lapso de tiempo, el periodo transcurrido entre la deposición o construcción de dos unidades consecutivas. Un hiato se reconoce justamente por carecer de representación material, hecho que se refleja en el diagrama por la comparación con otros casos semejantes. Tan sólo podrá reconocerse cuando no se haya producido un vacío erosional o superficie negativa entre dos elementos, dado que su acción nos ocultaría entonces el hiato.

De acuerdo a esta conclusión, se nos plantea de qué forma identificar los hiatos como tales, es decir, como horquillas temporales no representadas. La secuencia estratigráfica de un yacimiento muestra una consecución de unidades, entre las cuales, la ausencia de evidencias materiales impide afirmar la existencia de otras intermedias desaparecidas, cuya memoria sería difícilmente recuperable sin una documentación complementaria. Nos parece sugestivo mirar a la estratigrafía del yacimiento de cualquier espacio urbano, difícil de abarcar y similar al modelo de registro que efectúa la geología para reconocer su estratigrafía, que como hemos indicado al comienzo sufre por la ausencia de columnas estratigráficas completas. Igualmente, el edificio estará afectado por esta carencia y por lo tanto no podrá aportar nunca una secuencia que nos permita afirmar que es completa. Si la recuperación de materiales de fases previas en unidades de épocas posteriores puede reflejar que la discontinuidad encierra un vacío erosional y, del mismo modo, su ausencia puede interpretarse como un hiato, como sería el caso del abandono o despoblamiento de un yacimiento, en la arquitectura, por el contrario, el material reutilizado en etapas ulteriores no implica la necesaria existencia de una obra previa en el lugar.

En conclusión, será a partir de las superficies negativas (desmonte, derrumbe, destrucción) cuando podamos documentar las lagunas estratigráficas. Sin embargo, en el caso de que se produzca una fuerte transformación que suponga la eliminación completa de un elemento y que las alteraciones posteriores impidan constatar la superficie negativa, como ejemplificaba el caso de las cubiertas de Losa, la unidad sólo podrá ser recuperada gracias a la obtención de documentación complementaria. Por lo tanto, con el término de laguna estratigráfica se englobaría tanto a los hiatos como a los vacíos erosionales.

12 Sin olvidar además la posibilidad indicada por Vázquez de Parga

(1950) de que los documentos mencionados sean falsos. 


\section{Bibliografía}

Caballero Zoreda, L., 1995, Método para el análisis estratigráfico de construcciones históricas o "lectura de paramentos», Leer el documento construido (número monográfico) Informes de la Construcción, vol. 46,

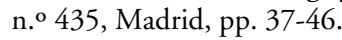

—, 1996, El análisis estratigráfico de construcciones históricas, en Id. y Escribano Velasco C. (eds.), Arqueología de la Arquitectura. El método arqueológico aplicado al proceso de intervención en edificios históricos (Burgos), "Actas», Junta de Castilla y León, Salamanca, pp. 55-74.

-, (Coord.), 2002, La Iglesia de San Millán de Suso (La Rioja). Lectura de Paramentos, C.S.I.C., Memoria depositada en el Instituto del Patrimonio Histórico Español, Madrid.

—, Arce, F. y Utrero, M.a A., 2003, San Esteban de Atán (Lugo): un ejemplo de iglesia que no es lo que parece, Arqueología de la Arquitectura, 2, pp. 63-68.

-, (Coord.), 2003a, Iglesia de Nuestra Señora de la Asunción de Viñaspre (Álava). Lectura de Paramentos, C.S.I.C., Memoria depositada en el Servicio de Patrimonio Histórico Arquitectónico de la Excma. Diputación Foral de Álava.

-, (Coord.), 2003b, Iglesia de San Martín de Arlucea (Álava). Lectura de Paramentos, C.S.I.C., Memoria depositada en el Servicio de Patrimonio Histórico Arquitectónico de la Excma. Diputación Foral de Álava.

-, (Coord.), 2003c, Ermita de San Pantaleón de Losa (Burgos). Lectura de Paramentos, C.S.I.C., Memoria depositada en la Dirección General de Patrimonio y Promoción Cultural de la Junta de Castilla y León, Valladolid.
—, y Murillo Fragero, J. I., 2004, Cómo se construye una torre mudéjar. La torre de la iglesia de San Pedro el Viejo de Madrid, Arqueología de la Arquitectura, 3, pp. 39-60.

—, 2005, La Iglesia de San Millán de la Cogolla de Suso. Lectura de paramentos 2002, Coord. Gil-Díaz Usandizoga, I., Arte Medieval en La Rioja: prerrománico y románico, VIII Jornadas de Arte y Patrimonio Regional, Gobierno de La Rioja, pp. 13-93.

Murillo Fragero, J. I. y NúÑez Herrero, M., 2005, Un ejemplo de Arqueología de la Arquitectura: la iglesia románica de San Pantaleón de Losa, Revista de la Fundación del Patrimonio Histórico de Castilla y León, 21, pp. 23-34.

Carandini, A., 1997, Historias en la Tierra. Manual de excavación arqueológica, Barcelona (Torino, 1991).

Dabrio, C. J. y Hernando, S., 2003, Estratigrafía, Universidad Complutense de Madrid.

Gómez Gómez, A. 2002, San Pantaleón de Losa. Enciclopedia del Románico en Castilla y León: Burgos (Tomo III). Fundación Santa María La Real, vol. 8, pp. 1961-1974.

Gómez Moreno, M. 1919, Iglesias Mozárabes. Arte español de los siglos IX al XI, Madrid, pp. 288-309.

Harris, E. H., 1991, Principios de estratigrafía arqueológica, Barcelona (London, 1979).

ÍñIgueZ AlmeCh, F. A., 1941, La ermita de San Pantalón de Losa (Burgos), Revista Nacional de Arquitectura, 3, pp. 63-67.

Puertas Tricas, R. 1979, Planimetría de San Millán de Suso, Logroño.

Ubieto Arteta, A., 1973, Los primero años del Monasterio de San Millán, Príncipe de Viana, 34, 132-133, pp. 1-20, 181-200.

VÁzQuez De PARGA, L., 1950, Los documentos sobre las presuras del obispo Odoario de Lugo, Hispania, X/XLI, pp. 635-680. 